\title{
A morte anunciada nas mídias: estranhamentos, familiaridade e cotidiano
}

\author{
The death announced in the media: estrangement, \\ familiarity and daily life
}

MARTINS, Moisés de Lemos; CORREIA, Maria da Luz; VAZ, Paulo Bernardo e ANTUNES, Elton (Eds.). Figurações da morte nos média e na cultura: entre o estranho e o familiar. Braga: CECS, 2016. 300p. Disponível em: <http://www.lasics.uminho.pt/ojs/index.php/cecs_ ebooks/issue/view/208>. Acesso em: 12/01/2017.
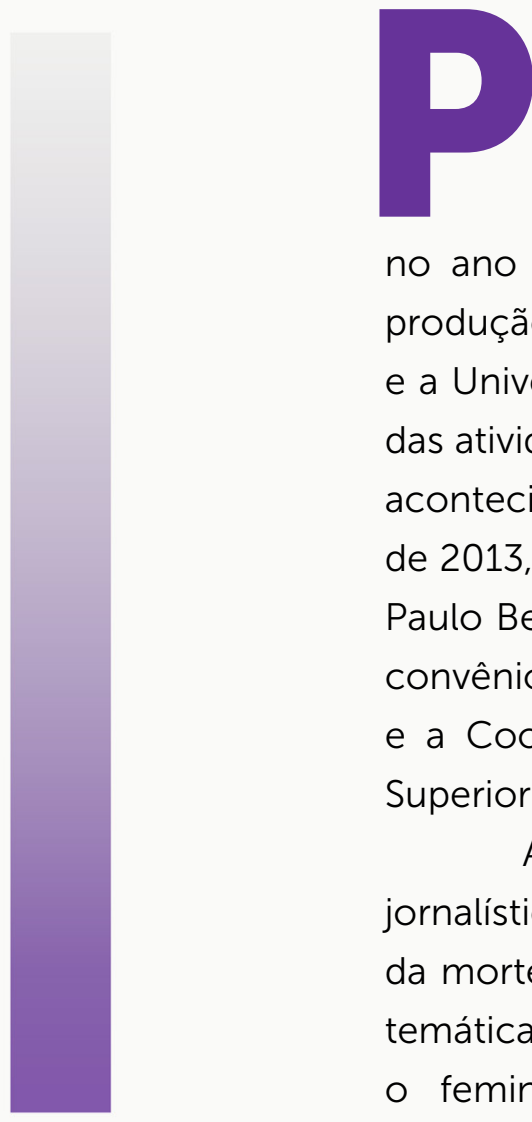

ensar o tema da morte na contemporaneidade a partir da abordagem jornalística é a proposta da coletânea Figurações da morte nos média e na cultura: entre o estranho e o familiar (Martins et al., 2016), publicada no ano de 2016, em formato de e-book. Trata-se de uma produção conjunta entre a Universidade do Minho, em Portugal, e a Universidade Federal de Minas Gerais, no Brasil, resultante das atividades do projeto de investigação "O fluxo, a morte e o acontecimento mediático: linguagens, interações e imaginário", de 2013, sob a coordenação de Moisés de Lemos Martins e de Paulo Bernardo Vaz, e com apoio financeiro baseado em um convênio entre a Fundação para a Ciência e a Tecnologia (FCT) e a Coordenação de Aperfeiçoamento de Pessoal de Nível Superior (CAPES).

Apresentando as maneiras pelas quais as mídias jornalística, impressa, televisiva e virtual publicizam a questão da morte nos dias atuais, o livro divide-se em quatro grandes temáticas: "Familiaridades da morte na cobertura mediática: o feminicídio"; "Da familiaridade à estranheza: morte e

* Graduada em Biblioteconomia pela Universidade Federal da Paraíba (UFP) e em História pela Universidade Federal de Uberlândia (UFU). Mestranda em História na Universidade Federal de Uberlândia (UFU), na área de História Social. CV: http://lattes.cnpq.br/7043766375672122 
acontecimento nos média"; "Estranheza da morte na moda, na fotografia e na publicidade: das estéticas às técnicas" e finalmente, "Álbum: visões da morte". Cada um desses blocos contém artigos que, embora tratem da mesma temática, o fazem a partir de abordagens, aportes teóricos, tratamento metodológico e temporalidades diferentes.

A motivação para a produção desta obra se deu a partir da percepção da quantidade de notícias veiculadas diariamente nos jornais e revistas, tendo a morte como personagem central. Logo, buscou-se entender de que maneira as mídias e as expressões culturais estão se apropriando dessas narrativas. Trata-se de um campo interdito para alguns, mas consentido para outros, uma vez que a morte é cada vez mais falada, conforme vemos confirmando-se a tese de Tony Walter (Walter, 1994). Obra de fôlego, rica em abordagens e minuciosa quanto à exposição das metodologias trabalhadas e os tratamentos teóricos adotados, a coletânea certamente é de grande utilidade para os pesquisadores dos temas que interpelam os estudos tanatológicos, como gênero, violência, imagem, fotografia, moda, jornalismo.

$\mathrm{Na}$ primeira das quatro partes, "Familiaridades da morte na cobertura mediática: o feminicídio", os autores se dedicam a traçar as maneiras pelas quais as matérias de jornais impressos, eletrônicos e mídia televisiva produzem as notícias e no que suas escolhas ajudam a reforçar o estereótipo, na sociedade brasileira contemporânea, de culpabilização da mulher pelas violências sofridas.

O capítulo "Crimes de proximidade e modos de aproximação: fronteiras narrativas", por intermédio de análise quantitativa busca mapear a tentativa da imprensa de afastar geograficamente as ocorrências de violência contra a mulher nos grandes centros urbanos para a periferia, a fim de transmitir uma falsa impressão ao leitor: "é como se os assassinatos e demais situações de violência de gênero só pudessem ocorrer em lugares 'distantes' (Leal, 2016, p.29). Por outro lado, os dois capítulos seguintes, "Crimes de proximidade em coberturas jornalísticas: de que mortes tratamos?" (Carvalho, 2016) e "Na cena da notícia: vestígios do jornalismo no assassinato de mulheres" (Antunes, 2016) traçam um perfil da violência contra a mulher, considerando as inúmeras circunstâncias que podem gerar tanto a violência quanto o noticioso sobre a mesma. Estes três primeiros capítulos exploram o conceito de crimes de proximidade e suas múltiplas possibilidades. Sem considerar os fatores sociais e culturais imbricados nas questões de gênero no Brasil, as notícias naturalizam o assassinato de mulheres, fortalecendo no imaginário coletivo a ideia de simples fatalidades. Esta é a perspectiva do capítulo "Silêncio visual e gritos verbais nas narrativas jornalísticas do feminicídio" (Vaz e Biondi, 2016). Apropriando-se do conceito de "museu imaginário", elaborado por André Malraux, em sua já clássica obra enciclopédica, de 1952, composta por quatro volumes, os autores do capítulo problematizam os componentes imagéticos das notícias, a partir das pistas que são dadas: tamanho e cor da letra, a fotografia da vítima e do assassino preso, como demais mecanismos utilizados para impactar o leitor.

O segundo bloco, composto por cinco capítulos, intitulado "Da familiaridade à estranheza: morte e acontecimento nos média", procura tratar dos modos de noticiar as mortes, por meio de um jornalismo voltado a estratégias que visam atrair o público com apelo às "sensações". Esta é a proposta de "A morte e o jornalismo nosso de cada dia". O autor 
explora a ideia da "imprensa de sensações", que atua não só no Brasil, mas em diversas partes do mundo, como uma "fórmula de despertar atenção 'cativa' dos leitores por meio de relatos mais dramáticos" (Portari, 2016, p. 91). Fica a questão: se a morte não se nomeia na sociedade contemporânea (Certeau, 1998), por que a mídia e, consequentemente, o público, se sentem tão fascinados por esse tema? Uma resposta possivel talvez seja o fato de a morte "romper com o quotidiano, especialmente quando está vinculada a atos de violência ou a tragédias", pois, conforme Nelson Traquina, a morte se constituiria como um "valor-notícia fundamental" (Traquina, 2005, p.79).

"A vertigem do momento: o poder do sofrimento e da morte e a ilusão da força das vítimas" (Araújo, 2016) é um estudo que busca refletir sobre as coberturas jornalísticas de desastres, por meio da análise de um caso ocorrido em Portugal, em 2001, quando do desabamento de parte da ponte Hintze Ribeiro, na região conhecida como Entre-os-Rios. A tragédia foi noticiada a partir do luto e das emoções dos familiares das vítimas, o que Araújo (apud Mayes, 2000) denomina de abordagem terapêutica (therapy news), cuja prioridade jornalística são as emoções dos envolvidos e não a objetividade da informação dos fatos. Julgadas as estratégias midiáticas, vê-se nessa exploração do sofrimento humano o empoderamento político das vítimas, embora, por mais das vezes, a sociedade assuma uma posição de impotência frente a algum pedido de explicação ao Estado.

Outra abordagem dada pela mídia no tocante à morte diz respeito ao modo como são tratados os casos de suicídio. Em "O suicídio de Walmor Chagas: acontecimento e contexto social contemporâneo" analisa-se o ocorrido com o ator Walmor Chagas, em 2013, a partir do conceito de "acontecimento", definido como "uma profusão de sentidos que emerge no mundo e afeta direta e indiretamente a vida das pessoas" (Simões e Ferreira, 2016, p. 133). Afeta a vida das pessoas porque se trata da trajetória de vida de uma figura pública, cuja identidade remete ao exemplo de vida a ser seguido, ao heroísmo, ao célebre, que constroem a sociedade atual juntamente com a massa de anônimos. O ocorrido com o ator Walmor Chagas levanta questões sobre a velhice e o suicídio na sociedade contemporânea, sendo a morte a grande culpada pela interrupção de uma trajetória de vida que, no caso da figura pública, é o que se chama de morto notável, aquele de quem queremos nos despedir, mesmo sem termos qualquer intimidade.

Diferente de casos de morte envolvendo gêneros biográficos, a publicização de mortes ocorridas por surtos de doenças tem outra perspectiva: a da contagem dos mortos, o que ocorreu em Portugal após um surto de Legionella, em novembro de 2014. Para as autoras de "Doença do legionário: da mediatização da doença à contagem das mortes", vivemos em um contexto em que a Comunicação em Saúde avalia o modo como é feita a comunicação, quanto aos cuidados com a saúde e que influenciam na tomada de decisões da comunidade médica. De acordo com as autoras "de longe, sempre de longe, os jornalistas foram os nossos olhos diante da morte. Contaram as vítimas e contaram-nos o horror da morte" (Gomes e Lopes, 2016, p. 148), cabendo, inclusive, um debate ético quanto a esta abordagem, em que as emoções são tratadas de modo sensacionalista, visando o entretenimento.

Já nos casos de erro médico, a imprensa portuguesa se utiliza do jornalismo como 
instrumento capaz de guiar o debate público, ao ter autonomia de decidir o que se tornará notícia. No capítulo "O erro médico na imprensa portuguesa: histórias de morte com uma só vítima" (Marinho, 2016), esta prática da autonomia da mídia portuguesa é analisada e gera alguns questionamentos, tais como: até que ponto os cidadãos devem ser informados sobre saúde e doença, de forma a serem auxiliados na tomada de decisões? Como a percepção dos cidadãos sobre esses temas são moldados pela mídia? Quando o erro médico resulta em mortes, seja por "ato de omissão" ou "erro por omissão", a maneira como são construídas as narrativas consideram a dimensão da perda de confiança da população no sistema de saúde?

Considera-se que há quatro vítimas desses erros: "o paciente; o profissional de saúde; a organização e o sistema de saúde" (Marinho, 2016, p. 171) e, de acordo com as fontes de informação, há um clamor por parte dos familiares das vítimas, com o objetivo de tornar os casos de erros médicos públicos, como forma de buscar "justiça". Os jornais portugueses, nesse sentido, dão espaço à indignação dos familiares a partir do uso de termos carregados de sentido, como "desabafo", "emoção", "angústia", "revolta", "trágico". (Marinho, 2016, p. 177). De modo geral, os três jornais portugueses analisados trataram como vítimas apenas os familiares e o paciente.

Na terceira parte da coletânea, "Estranhezas da morte na moda, na fotografia e na publicidade: das estéticas às técnicas", composto por quatro estudos, o foco são as imagens. O estudo "Declinações trágicas, barrocas e grotescas na moda contemporânea" (Martins, 2016) aponta para o modo como a indústria cultural da moda reflete os enigmas da condição humana, caldados na melancolia contemporânea. Para o autor, não só o jornalismo, mas o cinema e as artes de modo geral utilizam mecanismos estéticos para tratar do tema da morte. A análise da moda contemporânea é também um caminho possível nesta pesquisa de percepção da sociedade, sobretudo para o entendimento de que vivemos em um mundo cada vez mais pautado pelo regime da linguagem para o regime da imagem.

No tocante à fotografia, "No negativo: morte e fotografia" (Correia, 2016) discute a relação entre fotografia e morte, considerando os seus primórdios, em fins do século XIX, em cujas imagens havia o predomínio do macabro e do sobrenatural, mas também uma perspectiva lúdica e humorística. Nesse sentido, analisa as fotografias pós-morte, de ausentes e de vertente espírita, sob o viés do humor. A sociedade contemporânea teria encontrado na fotografia o recanto que a religião teria deixado de dar. No século XIX era uma prática comum tirar retratos fotográficos com entes queridos mortos, mas havia ainda a fotografia das pessoas sem cabeça, que compunha o universo risível do macabro. Assim, são gêneros fotográficos que refletiam as inquietudes de uma época que, se observadas hoje, ainda se encontram presentes, embora em outros suportes.

Mais dois capítulos compõem este terceiro bloco: "Três figurações do corpo sofredor no fotojornalismo" (Biondi, 2016) e "A morte como produto e objeto do desejo: uma abordagem publicitária" (Melo, 2016). Os elementos visuais que compõem as representações do corpo, que sofre com a angústia e a dor, são o centro de estudos das autoras. Enquanto a primeira autora traça os dispositivos da linguagem do fotojornalismo, a segunda procura compreender a linguagem da publicidade e suas estratégias de mediatizar a morte. 
A última e quarta parte, intitulada "Álbum/Visões da morte" tem dois estudos: "Morte e poder na obra de Gil Vicente: uma apresentação da série Inimigos (2005-2010)" (Palhares e Martins, 2016) e "Anúncios da Morte" (Gonçalves, 2016). Segundo os organizadores da coletânea, esta parte seria "uma espécie de galeria de visões onde a violência e a morte andam paredes-meias com a arte e a iconografia social quotidiana, da atualidade noticiosa à publicidade", contemplando assim o que se espera das possibilidades de aplicativos no "formato de um e-book": anexos visuais, breves posts, links de vídeos, endereços de blogues coletivos, indicação de redes sociais (Martins e Correia, 2016, p. 13).

Ao findar a leitura de obra tão vasta e diversificada fica a certeza de sua importância para os pesquisadores consagrados, professores experientes e investigadores iniciantes nos estudos sobre a morte, pela promoção de um profícuo debate que seus autores produzem acerca dos códigos culturais que identificam as sociedades contemporâneas.

\section{Referências Bibliográficas}

ANTUNES, Elton. Na cena da notícia: vestígios do jornalismo no assassinato de mulheres. In: MARTINS, Moisés de Lemos et al. (Eds.). Figurações da morte nos média e na cultura: entre o estranho e o familiar. Braga: CECS, p. 49-69, 2016.

ARAÚJO, Pedro. A vertigem do momento: o poder do sofrimento e da morte e a ilusão da força das vítimas. In: MARTINS, Moisés de Lemos et al. (Eds.). Figurações da morte nos média e na cultura: entre o estranho e o familiar. Braga: CECS, p. 113-130, 2016.

BIONDI, Angie Gomes. Três figurações do corpo sofredor no fotojornalismo. In: MARTINS, Moisés de Lemos et al. (Eds.). Figurações da morte nos média e na cultura: entre o estranho e o familiar. Braga: CECS, p. 227-245, 2016.

CARVALHO, Carlos Alberto de. Crimes de proximidade em coberturas jornalísticas: de que mortes tratamos? In: MARTINS, Moisés de Lemos et al. (Eds.). Figurações da morte nos média e na cultura: entre o estranho e o familiar. Braga: CECS, p. 33-48, 2016.

CERTEAU, Michel. A invenção do cotidiano. 3ำ ed. Petrópolis: Editora Vozes, 1998. 320p.

CORREIA, Maria da Luz. No negativo: morte e fotografia. In: MARTINS, Moisés de Lemos et al. (Eds.). Figurações da morte nos média e na cultura: entre o estranho e o familiar. Braga: CECS, p. 207-226, 2016.

GOMES, Sofia; LOPES, Felisbela. Doença do legionário: da mediatização da doença à contagem das mortes. In: MARTINS, Moisés de Lemos et al. (Eds.). Figurações da morte nos média e na cultura: entre o estranho e o familiar. Braga: CECS, p. 145-168, 2016.

GONÇALVES, Albertino. Anúncios da Morte. In: MARTINS, Moisés de Lemos et al. (Eds.). Figurações da morte nos média e na cultura: entre o estranho e o familiar. Braga: CECS, p. 275-299, 2016.

LEAL, Bruno Souza. Crimes de proximidade e modos de aproximação: fronteiras narrativas. In: MARTINS, Moisés de Lemos et al. (Eds.). Figurações da morte nos média e na cultura: entre o estranho e o familiar. Braga: CECS, p. 19-32, 2016. 
; ANTUNES, Elton e VAZ, Paulo Bernardo Ferreira. Agendamento, enquadramento e noticiabilidade. In: BENNETI, Márcia; FONSECA, Virgínia Pradelina da Silveira. (Org.), Jornalismo e acontecimento: mapeamentos críticos (Vol. 1). Florianópolis: Editora Insular, p. 187-219, 2010.

MALRAUX, André. Le Musée Imaginaire de la Sculpture Mondiale. Paris: NRF, 1952. 775p.

MARINHO, Sandra. O erro médico na imprensa portuguesa: histórias de morte com uma só vítima. In: MARTINS, Moisés de Lemos et al. (Eds.). Figurações da morte nos média e na cultura: entre o estranho e o familiar. Braga: CECS, p. 169-184, 2016.

MARTINS, Moisés de Lemos. Declinações trágicas, barrocas e grotescas na moda contemporânea. In: MARTINS, Moisés de Lemos et al. (Eds.). Figurações da morte nos média e na cultura: entre o estranho e o familiar. Braga: CECS, p. 187-205, 2016.

MARTINS, Moisés de Lemos. e CORREIA, Maria da Luz. Pensar a morte na contemporaneidade. In: MARTINS, Moisés de Lemos et al. (Eds.). Figurações da morte nos média e na cultura: entre o estranho e o familiar. Braga: CECS, p. 5-16, 2016.

MARTINS, Moisés de Lemos et al (Eds.). Figurações da morte nos média e na cultura: entre o estranho e o familiar. Braga: CECS, 2016.

MAYES, Tessa. Submerging in 'therapy news'. British Journalism Review. Londres, v. 11, n. 4, p. 30-36, dez. 2000 .

MELO, Ana Duarte. A morte como produto e objeto do desejo: uma abordagem publicitária. In: MARTINS, Moisés de Lemos et al. (Eds.). Figurações da morte nos média e na cultura: entre o estranho e o familiar. Braga: CECS, p. 247-264, 2016.

PALHARES, Ana Carmen; MARTINS, Moisés de Lemos. Morte e poder na obra de Gil Vicente: uma apresentação da série Inimigos (2005-2010). In: MARTINS, Moisés de Lemos et al. (Eds.). Figurações da morte nos média e na cultura: entre o estranho e o familiar. Braga: CECS, p. 267274, 2016.

PORTARI, Rodrigo. A morte e o jornalismo nosso de cada dia. In: MARTINS, Moisés de Lemos et al. (Eds.). Figurações da morte nos média e na cultura: entre o estranho e o familiar. Braga: CECS, p. 89-111, 2016.

SIMÕES, Paula; FERREIRA, Juliana. O suicídio de Walmor Chagas: acontecimento e contexto social contemporâneo. In: MARTINS, Moisés de Lemos et al. (Eds.). Figurações da morte nos média e na cultura: entre o estranho e o familiar. Braga: CECS, p. 131-144, 2016.

TRAQUINA, Nelson. Teorias do Jornalismo II. A tribo jornalística - uma comunidade interpretativa transnacional. V.2. Florianópolis: Insular, 2005.

VAZ, Paulo Bernardo Ferreira e BIONDI, Angie Gomes. Silêncio visual e gritos verbais nas narrativas jornalísticas do feminicídio. In: MARTINS, Moisés de Lemos et al. (Eds.). Figurações da morte nos média e na cultura: entre o estranho e o familiar. Braga: CECS, p. 71-86, 2016.

WALTER, Tony. The Revival of Death. London/New York: Routledge, 1994. 228p.

Recebido em: 31 de maio de 2017

Aprovado em: 01 de fevereiro de 2018 